\title{
FOTOGRAFIA NA HISTÓRIA DA ARTE
}

Marina Takami ${ }^{1}$

\section{Resumo}

A produção artística atual requer uma revisão das terminologias e das formas de abordar o objeto. Os limites que separavam as diferentes linguagens artísticas foram diluídos. A imagem fotográfica tem presença marcante na produção de arte contemporânea. Neste sentido é relevante que as discussões alcancem as fronteiras mais amplas das artes visuais. $\mathrm{Na}$ ocasião da aceitação da fotografia pelo mercado tradicional de arte, ela perdeu, oportuna e momentaneamente, uma de suas características principais: a reprodutibilidade. A fotografia garantiu sua entrada na história da arte por meio de empréstimos estéticos da pintura. Este ensaio aponta algumas reflexões sobre a imagem fotográfica a partir da leitura dos textos "O fotográfico", de Rosalind Krauss, e "La fotografía plástica: un arte paradójico”, de Dominique Baqué.

\section{Palavras-chave: fotografia, arte, história, fotográfico, fotografia plástica.}

\section{Resumen}

La producción artística actual necesita de una revisión de las terminologías y de las formas de abordar el objeto. Los límites que separaban los diferentes lenguajes artísticos se diluyeron. La imagen fotográfica tiene una fuerte presencia en la producción del arte contemporáneo. En este sentido es relevante que las discusiones alcancen las fronteras más amplias de las artes visuales. En el momento de la aceptación de la fotografía por el mercado tradicional de arte, ella perdió, oportuna y momentáneamente, una de sus principales características : la reproductibilidad. La fotografía aseguró su entrada en la historia del arte por medio de prestamos estéticos de la pintura. Este ensayo hace consideraciones acerca de la imagen fotográfica partiendo de la lectura de los textos "Lo fotográfico", de Rosalind Krauss, y "La fotografía plástica: un arte paradójico", de Dominique Baqué.

Palabras llaves: fotografía, arte, historia, fotográfico, fotografía plástica.

Se alguma coisa caracteriza a relação moderna entre a arte e a fotografia, é a tensão ainda não resolvida que surgiu entre ambas quando as obras de arte começaram a ser fotografadas (BENJAMIN, 1987a, p. 104).

Consideremos que o aprimoramento técnico da fotografia desde sua apresentação pública em 1839 na França, acompanhado pela redução dos preços de aquisição de uma imagem, foi determinante na popularização da técnica fotográfica no século XIX e deu-se de maneira acelerada. Podemos dizer também que a aceitação da fotografia como uma forma possível de expressão artística não foi tão ligeira. A fotografia se coloca entre a arte e a ciência desde sua origem. Ela se constitui de ambigüidades e contradições, por isso é fácil admiti-la tanto no território da verossimilhança como no da fantasia.

O surgimento e o desenvolvimento da fotografia foram importantes no processo de reformulação pictórica. As mudanças nas condições de produção da imagem derrubaram conceitos como tradição, autenticidade, autoria, existência única e valor eterno, referidos

\footnotetext{
${ }^{1}$ Universidade de São Paulo
} 
pelo filósofo Walter Benjamin (1892-1940) no texto sobre a obra de arte e sua reprodutibilidade técnica, escrito em 1935/1936². A fotografia como imagem técnica, suficientemente verossímil, conseguida a partir do real e com capacidade de reprodutibilidade, abriu possibilidades para toda a pesquisa moderna que se seguiu, sobretudo à pintura. A primeira exposição dos pintores impressionistas ocorreu no estúdio do fotógrafo Gaspard-Félix Tournachon, o Nadar (1820-1910), em 1874, neste momento é difícil dizer se era maior o interesse do fotógrafo por aqueles pintores on o dos pintores pela fotografia (ARGAN, 2001, p. 75).

As primeiras fotografias foram atormentadas pelo fantasma da pintura. Porém, como observou Roland Barthes (1915-1980), pelo teatro a fotografia também pode se relacionar com a arte. Ela assume o papel de máscara, uma imagem cujo espetáculo é nítido, e utiliza-se de atributos para representar a promoção social (1984, p. $78-80)$. A câmara escura era utilizada por pintores já antes da descoberta da fotografia e posteriormente foi adotada pelos fotógrafos, que uniram a ela as descobertas químicas do século XIX. As referências que fazemos entre pintura e fotografia têm origem nas suas coincidências de enquadramento e perspectiva. O jogo de cena que existe a partir da câmera escura está presente tanto no ilusionismo dos quadros perspectivos e dioramas de Louis Jacques Mandé Daguerre (1787-1851) quanto na própria fotografia (BARTHES, 1984, p.52-53). Os retratos de estúdio oitocentistas, principalmente os carte-de-visites ${ }^{3}$, difundiram a fotografia por todas as classes assumindo como necessária a encenação que prepara o retratado para o registro. A aproximação ingênua do retrato fotográfico a pintura, feita por fotógrafos retratistas, através do referencial estético de poses e acessórios não poderiam garantir o reconhecimento da técnica fotográfica como arte. Como nos aponta Walter Benjamin ao citar uma publicação inglesa especializada em fotografia:

Nos quadros pintados a coluna tem ainda um simulacro de probabilidade, mas o modo como ela é aplicada na fotografia é absurdo, porque ela se ergue em geral sobre um tapete. Ora, todos estão de acordo em que não é sobre um tapete que se constroem colunas de mármore ou de pedra. (1987a, p. 98).

A negação do estatuto artístico à fotografia originou experiências como a do artista Oscar Gustave Rejlander (1813-1875), que criou uma fotografia alegórica em 1857, "Os dois caminhos da vida", com a utilização de pelo menos 30 negativos. O autor queria que sua obra, bastante elaborada, pudesse ser julgada segundo os mesmos critérios aplicáveis à pintura até então. Rejlander expôs o potencial de montagem da fotografia, demonstrado também no seu texto On Photographic Composition (Sobre Composição Fotográfica), apresentado à Photographic Society em 1858 (PAVAN, 1998, p. 253), onde manifesta-se contra preconceitos relacionados à fotografia. Esta composição fotográfica de Rejlander justifica o reconhecimento da fotografia como arte na medida em que as preocupações do

\footnotetext{
${ }^{2} \mathrm{O}$ ensaio A obra de arte na era de sua reprodutibilidade técnica possui duas versões com diferenças a serem consideradas como, por exemplo, a presença de subtítulos na $1^{\mathrm{a}}$ versão. A $2^{\mathrm{a}}$ versão foi a primeira a ser traduzida para o português, foi publicada em A idéia do cinema (Rio de Janeiro, Civilização Brasileira, 1969), na coleção Os Pensadores (Abril Cultural) e em Teoria da cultura de massa (6 edição - São Paulo, Paz e Terra, 2000). A $1^{\text {a }}$ versão foi publicada em português na coleção de obras escolhidas de Walter Benjamin pela editora Brasiliense em 1985 (1 ${ }^{\text {a }}$ edição), este artigo faz referência à esta $1^{\text {a }}$ versão.

3 Este formato permitia a obtenção de oito retratos de aproximadamente $6 \mathrm{x} 9 \mathrm{~cm}$ num único clichê de tamanho convencional. Estas fotografias eram coladas em cartões do estúdio onde eram produzidas contendo normalmente nome e endereço do fotógrafo. A principal aplicação deste formato foi em retratos, mas também podemos encontrar paisagens e outros temas.
} 
fotógrafo eram as mesmas do pintor no planejamento da composição. A justificativa do artista não era das mais plausíveis na medida em que não considerava aspectos específicos do fotográfico. No entanto, a questão levantada era relevante e naquele instante não foi identificada sua devida importância.

O movimento de fotógrafos conhecidos como pictorialistas foi bastante significativo para o reconhecimento do potencial artístico da fotografia. A herança pictórica está bem clara na denominação do movimento. A seu modo, o pictorialismo foi uma reação à massificação da fotografia, evidente a partir da industrialização de equipamentos e materiais em meados do século XIX. Por meio de técnicas apuradas, como por exemplo a goma bicromatada, que aproximavam a imagem fotográfica da gravura, da aquarela e da própria pintura, estes fotógrafos devolveram à fotografia o caráter de unicidade existente na arte pictórica e mesmo nas primeiras técnicas fotográficas como, por exemplo, o daguerreótipo. Se tomarmos pelo inverso, os pictorialistas retiraram da fotografia a sua qualidade de reprodução que trouxe transformações a diferentes esferas da vida. Estes fotógrafos se organizavam em grupos que derem origem aos fotoclubes, círculos freqüentados por uma elite econômica. Os pictorialistas recolocaram a fotografia num patamar inacessível à maioria devido à circulação restrita do objeto único. Trata-se de uma postura romântica que ignora as especificidades da fotografia:

\footnotetext{
O dado positivo da atividade pictorialista foi dar à fotografia o estatuto de obra de arte e permitir a uma camada de aficionados da burguesia acesso à expressão artística (COSTA; SILVA, 2004, p. 27).
}

O debate da fotografia como meio de expressão artística em si remonta ao século XIX. Entretanto, a discussão sobre a importância da reprodução da arte como fotografia foi escassa ou quase nula (BENJAMIN, 1987a, p.104), o que não impediu que a sociedade, naquele momento, usufruísse a reprodução fotográfica. Este debate abre caminho para reflexões que não são exclusivas da fotografia e da obra de arte.

Em 1932 a exposição Murals by American Painters and Photographers (Murais de pintores e fotógrafos americanos) no Museu de Arte Moderna de Nova York (MoMA) apresentou ampliações murais de imagens de fotógrafos como Berenice Abbott (18981991) e Edward Steichen (1879-1973). Em 1933, no mesmo museu, aconteceu a exposição do fotógrafo Walker Evans (1903-1975) e logo depois a mostra Photography 1839-1937 (Fotografia 1839-1937), organizada por Beumont Newhall, que são passos importantes para entrada da fotografia no museu, espaço antes dedicado somente às belas artes que excluía a fotografia. Por fim a criação do Departamento de Fotografia do MoMa em 1940, a abertura do Museu Internacional de fotografia de Rochester em 1949, a ocorrência de grandes mostras fotográficas em reconhecidos museus de arte e a criação de cursos e escolas de fotografia dedicados ao desenvolvimento da expressão artística são bases sólidas que legitimam o estatuto artístico da técnica. Inaugurada a institucionalização da imagem fotográfica, não sem custos às qualidades de reprodutibilidade da técnica ${ }^{4}$, diferentes museus do mundo terão suas coleções e a fotografia tem seu caráter artístico assegurado.

Sabemos hoje que o desenvolvimento técnico da fotografia não cessa e que caminha no campo das ciências e, não menos, no campo das artes. $\mathrm{Na}$ arte contemporânea, a partir dos anos 1960, podemos dizer que os limites entre as diferentes técnicas artísticas

\footnotetext{
${ }^{4}$ As fotografias passam a ter séries numeradas e assinadas, nos moldes da gravura, e a reprodução do negativo é controlada. Estas medidas estão vinculadas à entrada da imagem fotográfica no mercado e comercialização de arte.
} 
não existem mais. Mais que isso, não há como determinar uma técnica como artística e excluir outras a partir do momento em que toda forma de expressão, com qualquer tipo de material ou sem matéria, pode ser entendida como artística, o que depende somente da intenção e do contexto onde isto se dá. Deste modo, não é preciso ir muito longe para compreender a necessidade de repensar a produção crítica e historiográfica da arte. Para que possamos englobar numa mesma terminologia as mais diferentes formas de expressão artística definidas no universo das artes plásticas podemos adotar a denominação artes visuais, que amplia esta idéia. Delimitando nossa discussão ao campo da fotografia, é notável em mostras de arte contemporânea a presença em massa da imagem fotográfica. $\mathrm{Na}$ reflexão sobre fotografia na história da arte destaco os conceitos de fotográfico, do livro de Rosalind Krauss e de fotografía plástica, do livro de Dominique Baqué.

Rosalind Krauss no livro "O fotográfico" propõe analisar diferentes territórios das artes a partir deste 'objeto teórico', o fotográfico. Ele não se aplica somente à arte contemporânea, a partir dos anos 1960, mas pode servir para a realização de uma nova leitura de movimentos anteriores como, por exemplo, o surrealismo, tema explorado por Krauss no fim do capítulo II. A fotografia traz o que a autora chama de 'calibragem teórica', uma 'calibragem fotográfica'. Os textos reunidos neste livro foram escritos em diferentes ocasiões e têm em comum a abordagem deste 'objeto teórico', o fotográfico:

\begin{abstract}
nos ensina a essência problemática de toda história da fotografia, como já tinha tornado essencialmente problemática a transposição do discurso crítico da arte no plano da fotografia. Pode-se escrever uma história da arte, mas nunca será o mesmo tipo de história que se escreverá sobre a fotografia." (KRAUSS, 2002, p.17).
\end{abstract}

A condição semiológica de índice da fotografia implica transformações no universo da arte. Krauss trabalha com a concepção de signo do teórico americano Charles Sander Peirce (SANTAELLA, 2000). A autora, ao partir para o terreno da fotografia, questionou a mídia buscando o que lhe era próprio. Não satisfeita com um projeto crítico sobre o objeto fotográfico, dá continuidade e "se atêm ao fato de que a fotografia é um objeto teórico e incide de maneira reflexiva tanto sobre o projeto crítico como sobre o projeto bistórico que a escolhem como objeto." (KRAUSS, 2002, p.17). Deste modo estes ensaios versam a partir da fotografia e não sobre ela.

No capítulo de abertura do livro Krauss refere-se às memórias de Nadar, Quand j'étais photographe (Quando eu era fotógrafo), onde, pelo título, tende a nos mostrar que a escrita centrar-se-á na experiência do autor com a fotografia, mas ao avançar a leitura do livro vemos que Nadar parece afastar-se da fotografia para ao mesmo referir-se a ela. Ele escreve suas memórias como testemunha que tinha senso de responsabilidade do que presenciou. O autor dedica grande parte do livro a anedotas e descrições de detalhes de experiências pessoais e somente no último capítulo se detém de fato à fotografia. Nadar deseja divulgar a fotografia destacando-a como um invento de enorme significância no contexto do seu surgimento e no que se seguiu; para tanto, não lhe interessa o "quem", o "quê" e o "quando" da fotografia (KRAUSS, 2002, p.22). Nadar soube reconhecê-la como fenômeno histórico, observou a necessidade do objeto ter estado fisicamente diante da sua representação (o que a semiótica define como traço, característica do índice) e surpreendeuse com a transformação de algo mágico e misterioso em fato corriqueiro. Nadar evoca o ambiente de surgimento da fotografia e relativiza sua história de futuro incerto. O título deste capítulo do livro de Rosalind Krauss é uma pergunta, 'A expressão 'História da fotografia' refere-se a um objeto de pensamento existente?’, que não será mais respondida 
que problematizada. No final da segunda parte deste capítulo a autora interessa-se pelo imenso arquivo de 10.000 fotografias de Eugène Atget (1857-1927) e chega a uma das questões centrais da história da fotografia, os mecanismos de legitimação estética. Quando os códigos dos negativos de Atget foram decifrados concluiu-se que não possuíam referência estética e que se tratava de um catálogo sistematizado. Os detentores da chave deste arquivo resistiram em usá-la porque, ao invés de revelar as intenções estéticas de Atget, a chave as faz desaparecer e assim encerra a suposta pretensão artística do fotógrafo. A questão importante revelada por Krauss a partir destas fotografias relaciona-se ao desmantelamento do

$$
\begin{aligned}
& \text { arquivo fotográfico, quer dizer, o conjunto das práticas, instituições, relações de } \\
& \text { onde surgiu inicialmente a fotografia do século XIX, para reconstruí-lo no quadro } \\
& \text { das categorias já constituídas pela arte e sua história (KRAUSS, 2002, p.56). }
\end{aligned}
$$

$\mathrm{Na}$ leitura que Rosalind Krauss faz da obra "La mariée mise à nude par ses célibataires, même" (A noiva despida por seus celibatários, mesmo) de 1915-1923, conhecido como o "Grande vidro", de Marcel Duchamp (1887-1968) vê o artista preocupado com a reflexão sobre a natureza do fotográfico. A implicação de Duchamp com a fotografia pode ser percebida em trabalhos anteriores em que usou direta e indiretamente a referência fotográfica. Krauss chama a atenção para a ausência da constatação deste apego de Duchamp ao fotográfico nos inúmeros estudos sobre o artista. Isto é revelador do sistema de hierarquias das artes figurativas onde a fotografia é qualificada no mais baixo escalão. Krauss procura elos específicos entre o "Grande Vidro" e o fotográfico; o primeiro que encontra é a transparência da obra. $\mathrm{O}$ vidro abre a superfície para o contato direto e constante com o real. A segunda ligação está na relação da fotografia com a legenda, com o texto explicativo. No caso do "Grande Vidro", o título é sugestivo e não revela os enigmas da obra. Mesmo nas 'Notas' para o "Grande Vidro", publicadas em 1934, Duchamp mantêm os mistérios. No entanto, ao revelar nestas 'Notas' alguns procedimentos de realização da obra o artista nos informa sobre os vínculos do "Grande Vidro" com a fotografia. Sabe-se, por exemplo, que "os pistões de corrente de ar" são resultantes de três momentos fotográficos que, ao serem transferidos para o "Grande Vidro", deixaram de ser fotografias mas mantiveram o aspecto de traço da produção. Desta forma o fotográfico está presente nesta obra de Duchamp pelo seu caráter indicial. O registro ou o traço nem sempre se parece com aquilo que representa, como estamos acostumados na fotografia de sombras ou no fotograma. Segundo Krauss,

$$
\begin{aligned}
& \text { o que a arte de Duchamp sugere é que esta mudança da forma das imagens que se } \\
& \text { constituem progressivamente no nosso entorno arrasta consigo uma mudança na } \\
& \text { estrutura dominante da representação. [...] Isto quer dizer que o modo de } \\
& \text { produção dos signos afeta os próprios processos do conhecimento (KRAUSS, } \\
& \text { 2002, p.92). }
\end{aligned}
$$

Numa trajetória diferente, mas ainda referindo-se às relações entre arte e fotografia, o livro "Fotograíia Plástica: un arte paradójico" (Fotografia Plástica: uma arte paradoxal), de Dominique Baqué traz um ensaio sobre a fotografia que está na fronteira entre o que chamaríamos de história da arte e história da fotografia. Baqué versa sobre a fotografia considerando suas ambigüidades, contradições e paradoxos. A fotografia de que trata a autora é aquela utilizada por artistas,

que não se inscreve em uma história do meio supostamente pura e autônoma, pelo contrário, é aquela que atravessa as artes plásticas e participa da hibridização, da desaparição, cada vez mais manifesta, das separações entre os diferentes campos de produção (BAQUÉ, 2003, p.9). 
O paradoxo de entrada da fotografia no campo das artes ditas plásticas se desfaz em fins dos anos setenta quando a fotografia converte-se na própria obra. É neste período que o neologismo 'fotografia plástica' se cristaliza, reivindicado por fotógrafos e renegado pelo discurso crítico. De algum modo parece que tudo já estava posto, latente na arte conceitual, na land art e nas artes de atitude (performance, happening). Estas manifestações artísticas se inscrevem como marcos que buscaram eliminar as fronteiras entre arte e vida e que, para isso, criaram novos procedimentos. A fotografia nas artes de atitude desempenha diferentes funções, no mínimo ambíguas quando não paradoxais, que vão desde a simples e pura documentação ao que poderia ser a obra mesmo. Como mostra a autora, quando o artista Dennis Oppenheim, na performance intitulada Reading Position for 2nd Degree Burn (Posição de leitura para queimadura de segundo grau) de 1970, usa a pele como suporte fotossensível, estabelece uma inversão da fotografia que documenta para aquela fotografia que rege e modela a performance. A pele é película fotográfica e o ato é eminentemente fotográfico. (BAQUÉ, 2003, p.16).

A separação entre a fotografia no campo das artes plásticas e a fotografia no campo específico do meio apresenta falhas teóricas, contradições e limites que devem ser admitidos. Há, paralelamente, posturas que perseguem uma história autônoma da fotografia e outras que pretendem inscrevê-la na prática das artes plásticas. Neste sentido, Baqué pondera que a entrada da fotografia no âmbito das artes plásticas abre possibilidades como a hibridização e a contaminação dos meios que constituem, sem dúvida, uma das principais determinações da arte contemporânea. Por outro lado, a 'fotografia criativa', corrente purista amparada pelas idéias de Jean-Claude Lemagny, sustenta que a fotografia deve se enquadrar nos atributos tradicionais da obra de arte e preservar sua história autônoma, não como possibilidade mas como necessidade. O paradoxo da fotografia plástica se coloca claramente em obras puramente fotográficas que de certo modo são concebidas em relação ao modelo pictórico, como teorizou Jean-Marc Bustamante no início dos anos oitenta com os termos "quadros fotográficos" e "foto-quadro". (BAQUÉ, 2003, p.45). Pensar que o estatuto da fotografia se estabilizou nos anos noventa é ilusório; como mostra Baqué, a fotografia, "meio precário e frágil, assediado pelo utilitário e pelo consumo, [...] constitui uma imagem ontologicamente incerta e pobre que não cessa de duvidar." (2003, p.47).

As legitimações teóricas da fotografia no campo das artes surgiram apenas nas primeiras décadas do século XX. Os primeiros textos que vêem a fotografia como objeto teórico são dos anos 1920 e 1930; cabe destacarmos o texto de Siegfried Kracauer ("A Fotografia", 1927) ${ }^{5}$ e os conhecidos ensaios de Walter Benjamin ("Pequena História da fotografia", 1931, e "A obra de arte na era da sua reprodutibilidade técnica", 1935-1936). Estes estudos demoram a aparecer e não têm continuidade imediata. Nos anos setenta a fotografia entra para o campo das artes plásticas e permanece com um corpus teórico bastante restrito. Baqué assinala a existência dos escritos de Gisèle Freund ("A fotografia como documento social", 1974) e de Susan Sontag ("Ensaios sobre fotografia", 1977) que apresentam uma visão de fotografia histórica com direcionamento sociológico. A legitimação teórica, pensada pelo critério da arte, surge nos anos oitenta com "A câmera clara: nota sobre a fotografia" (1980) de Roland Barthes. Esta visão é reforçada pelas investigações de Philipe Dubois ("O ato fotográfico", 1990) e de Rosalind Krauss ("O

\footnotetext{
${ }^{5}$ Este ensaio e outros escritos do autor são pouco conhecidos porque permanecem publicados somente no idioma original alemão. A versão referenciada neste artigo foi traduzida diretamente do alemão para o português por Carlos Eduardo Jordão Machado e está e vias de ser publicada.
} 
fotográfico", 1990) que entendem a fotografia segundo sua indicialidade. Dominique Baqué sublinha a postura de Rosalind Krauss:

\footnotetext{
Não se trata de pensar a fotografia segundo critérios em curso na história da arte, e sobretudo da pintura. Pelo contrário, diante do tema dominante de uma filiação da fotografia em relação à pintura, é conveniente pensar, na radical ruptura epistemológica induzida pela fotografia no regime de imagens do século XIX (2003, p.87).
}

No panorama brasileiro, os escritos teóricos demoraram ainda mais a serem conhecidos por artistas e pesquisadores tendo como obstáculos o idioma, a demora de traduções para o português e a inexistência (até hoje) de edições nacionais a custos mais acessíveis.

Por fim, referindo-me diretamente à concepção de Rosalind Krauss no livro "O Fotográfico", onde a autora pensa a fotografia como 'objeto teórico' e versa a partir dela e não sobre ela, talvez também caiba ponderarmos uma história da arte, sobretudo no âmbito da arte contemporânea, a partir de objetos artísticos mais que escrever uma história sobre estes objetos. Isto não se deve apenas pela relevância do fotográfico nas manifestações artísticas depois da fotografia, mas, também, para evitar encaixar-se forçosamente objetos artísticos em categorias, às vezes resistentes a transformações, que existem na história e na crítica e nas instituições que os legitimam enquanto arte.

De modo reflexivo e sem pretensões de ser exaustivo na exploração dos livros que serviram de partida para este ensaio, o presente texto é uma proposta de discussão aberta e, portanto, não conclusivo.

\section{Referências Bibliográficas}

ARGAN, Giulio Carlo. Arte moderna: do iluminismo aos movimentos contemporâneos. Tradução Denise Bottmann e Federico Carotti. São Paulo: Companhia das Letras, 2001. $710 \mathrm{p}$.

BAQUÉ, Dominique. La fotografía plástica: un arte paradójico. Tradução Cristina Zelich. Barcelona: Gustavo Gili, 2003. 288p.

BARTHES, Roland. A câmara clara: nota sobre a fotografia. Tradução Castanon Guimaraes. Rio de Janeiro: Nova Fronteira, 1984. 185p.

BENJAMIN, Walter. Pequena história da fotografia. In: Magia e técnica, arte e política: ensaios sobre a literatura e história da cultura. Tradução Sergio Paulo Rouanet. 3. ed. São Paulo: Brasiliense, 1987a. p. 91-107. (Obras Escolhidas, vol.1).

. A obra de arte na era da sua reprodutibilidade técnica. In: Magia e técnica, arte e política: ensaios sobre a literatura e história da cultura. Tradução Sergio Paulo Rouanet. 3. ed. São Paulo: Brasiliense, 1987b. p. 165-196. (Obras escolhidas, vol.1).

BOLTON, Richard. The contest of meaning: critical histories of photography. Massachusetts: MIT press, 1990. 407p.

COSTA, Helouise. SILVA, Renato Rodrigues. A fotografia moderna no Brasil. São Paulo: Cosac Naify, 2004. 224p.

DUBOIS, Philippe. O ato fotográfico e outros ensaios. Tradução Marina Appenzeller. 7. ed. Campinas: Papirus, 2003. 268p. (Série Ofício de Arte e Forma). 
KRAUSS, Rosalind. O fotográfico. Tradução Anne Marie Davée. Barcelona: Gustavo Gili, 2002. 240p.

PAVAN, Margot. Fotomontagem e pintura pré-rafaelista. In: FABRIS, Annateresa (org.). Fotografia: usos e funções no século XIX. 2 ed. São Paulo: EDUSP, 1998. Capítulo 8, p. 233-259 (Texto \& Arte, 3).

SANTAELLA, Lucia. A teoria geral dos signos: como as linguagens significam as coisas. São Paulo: Pioneira, 2000. 153 p. 